\title{
Amadurecimento de frutos de cubiu (Solanum sessiliflorum Dunal) tratados com Etefon
}

\author{
Suzana STEFANELLO ${ }^{1}$, Adilson Ricken SCHUELTER ${ }^{2}$, Carlos Alberto SCAPIM ${ }^{3}$, Fernando Luiz FINGER ${ }^{4}$, \\ Giselda Maria PEREIRA5, Carlos Moacir BONATO ${ }^{6}$, Andressa Camilo de Souza ROCHA7, \\ Jaqueline Manzatti SILVA ${ }^{8}$
}

\begin{abstract}
RESUMO
O presente trabalho teve como objetivo avaliar a qualidade pós-colheita de frutos de cubiu (Solanum sessiliflorum) durante o amadurecimento após o tratamento com Etefon. Frutos das variedades Santa Luzia e Thais no estádio verde-maduro foram coletados, lavados e pulverizados até o completo molhamento com $1000 \mathrm{mg} \mathrm{L}^{-1}$ de Etefon e o controle com água. A cada três dias, durante 12 dias foram realizadas análises da firmeza do pericarpo, $\mathrm{pH}$, teor de sólidos solúveis totais, acidez total titulável (ATT), umidade e cinzas. Foi avaliada a liberação de $\mathrm{C}_{2}$ e etileno diariamente durante 12 dias, conjuntamente com a perda de matéria fresca e evoluçáo da cor, a cada três dias, sempre no mesmo grupo de frutos. Foi empregado o delineamento experimental inteiramente casualizado. Os dados foram submetidos à análise de variância e análise de regressáo. Ocorreu perda de firmeza do pericarpo dos frutos com o tempo de armazenamento pós-colheita, com diminuiçáo do $\mathrm{pH}$, aumento da ATT e perda da matéria fresca. A aplicaçáo de Etefon promoveu poucas mudanças na qualidade interna dos frutos, porém foi eficiente no desverdecimento da casca, o que pode ser verificado pelos menores valores do ângulo de cor e maiores da cromaticidade e luminosidade. $\mathrm{O}$ comportamento da respiraçáo e produção de etileno aponta para um modelo de amadurecimento não climatérico.
\end{abstract}

PALAVRAS-CHAVE: Solanaceae, ácido 2-cloroetilfosfônico, qualidade físico-química, etileno.

\section{Postharvest ripening of Ethephon-treated cubiu (Solanum sessiliflorum Dunal) fruits}

\begin{abstract}
The objective of the present work was to evaluate postharvest quality of cubiu (Solanum sessiliflorum) fruits during ripening after Ethephon treatment. Fruits from the varieties Santa Luzia and Thais were harvested at green-mature stage, washed and sprayed until run off with Ethephon $\left(0\right.$ e $\left.1000 \mathrm{mg} \mathrm{L}^{-1}\right)$. At every three days, during 12 days, the following analyses were performed: pericarp firmness, $\mathrm{pH}$, total soluble solid content, total titratable acidity (ATT), water content and ashes. $\mathrm{CO}_{2}$ and ethylene production were evaluated daily for 12 days, together with the loss of fresh matter and color evolution, at every three days, always the same fruit group. The experiment was arranged in a complete randomized design. Data were examined by analysis of variance and regression analysis. There was loss of pericarp firmness with time of postharvest storage, with decrease in $\mathrm{pH}$, increase in ATT and loss of fresh matter. Ethephon promoted small changes in the internal quality of fruits, whereas it was efficient to induce degreening of fruit peel, which can be verified by the lower color angles and higher chromaticity and brightness. Respiration rates and ethylene production of the fruit suggest that cubiu has non-climateric behavior.
\end{abstract}

KEYWORDS: Solanaceae, 2-chloroethyl phosphonic acid, physical-chemical quality, ethylene.

\footnotetext{
${ }^{1}$ Universidade Paranaense, E-mail: sstefanello@zipmail.com.br

2 Universidade Paranaense, E-mail: adilson_schuelter@yahoo.com.br

${ }^{3}$ Universidade Estadual de Maringá, E-mail: cascapim@uem.br

${ }^{4}$ Universidade Federal de Viçosa, E-mail: ffinger@ufv.br

${ }^{5}$ Universidade Federal do Amazonas, E-mail: giseldamp@ufam.edu.br

${ }^{6}$ Universidade Estadual de Maringá, E-mail: cmbonato@uem.br

7 Universidade Paranaense, E-mail: andressacamilo@hotmail.com

${ }^{8}$ Universidade Paranaense, E-mail: jaquelinemanzatti@hotmail.com
} 


\section{INTRODUÇÃO}

O cubiu (Solanum sessiliflorum Dunal) é uma solanácea arbustiva nativa da Amazônia também conhecida como maná, topiro ou tomate de índio a qual foi domesticada pelas populações indígenas. A planta apresenta potencialidades para a agroindústria moderna, dada a sua rusticidade e alta produção de frutos. Os frutos são de tamanho variável, subglobosos a ovóides, do tipo baga, vermelho-alaranjados quando maduros, de polpa ácida com numerosas sementes achatadas (Storti 1988), variando entre 30 a $400 \mathrm{~g}$ (Marx et al. 1998).

Os frutos possuem elevados teores de niacina (Villachica 1996; Marx et al. 1998) e ferro (Silva Filho et al. 2005), sendo utilizados in natura ou nas mais diversas formas em sucos, doces, geléias, sorvetes, molhos, cosméticos (Silva Filho et al. 1999) e na medicina popular como agente hipoglicemiante e hipocolesterolêmico (Pardo 2004).

$\mathrm{Na}$ Amazônia, a floração ocorre durante os meses de setembro a novembro (Storti 1988), com início 4 ou 5 meses após a germinação (Silva Filho 2002). A produção de frutos inicia 7 meses após a semeadura (Marx et al. 1998; Silva Filho et al. 1999).

Nos últimos anos têm ocorrido crescente valorização do fruto no mercado brasileiro (Silva Filho et al. 2005) e a planta tem sido levada para outras regióes, incluindo a zona da mata pernambucana e em algumas localidades da região sudeste (Pires et al. 2006) e sul (Brancher e Tagliari 2004). Porém, o efeito das condições edafo-climáticas da região na qualidade dos frutos, nos constituintes químicos, no tamanho e na massa dos frutos ainda são pouco conhecidos, tornando a exploraçâo comercial bastante limitada.

Silva Filho (2002) relatou grande variabilidade genética para forma, tamanho, conteúdo de sólidos solúveis e produção de frutos de cubiu em populaçôes naturais da Amazônia. Hernández et al. (2004) relataram que frutos da Amazônia Colombiana apresentaram período de vida útil de 19 dias após a colheita a $15^{\circ} \mathrm{C}$ e padrão respiratório semelhante ao de frutos não-climatéricos. Porém, ainda há falta de conhecimento sobre as características fisiológicas dos frutos como a produção de etileno, a sensibilidade ao etileno exógeno e seu efeito sobre as características químicas de frutos durante o amadurecimento pós-colheita.

Estudos envolvendo a utilizaçáo de produtos que liberam etileno como o Etefon são úteis para distinguir frutos climatéricos e não-climatéricos, sendo essencial para definir o ponto de colheita, e técnicas de manipulação e armazenamento que possam ser usadas para prolongar a vida pós-colheita (Archbold e Pomper 2003). Além disso, frutos não-climatéricos, não exibem aumento na produçáo de etileno e na taxa de respiração, mas podem ser sensíveis ao regulador de crescimento durante a fase pós-colheita (Lelièvre et al. 1997).

Assim, o presente trabalho teve como objetivo avaliar o amadurecimento de frutos de Solanum sessiliflorum após o tratamento com Etefon.

\section{MATERIAL E MÉTODOS}

\section{MATERIAL VEGETAL E CONDIÇÕES DE CULTIVO}

Foram utilizados frutos de plantas de cubiu das variedades Santa Luzia e Thais cultivados na área experimental da Universidade Paranaense (UNIPAR), Toledo, PR (para determinação dos componentes físico-químicos) e da Universidade Federal de Viçosa (UFV), Viçosa, MG (para quantificação de gases) no ano agrícola 2006/2007.

As mudas com 45 dias, obtidas por meio de semeadura em bandejas preenchidas com substrato para hortaliças, foram transferidas para sacos de polietileno e após 75 dias transplantadas para covas de $0,2 \times 0,2 \mathrm{~m}$ de largura por 0,2 $\mathrm{m}$ de profundidade. $\mathrm{O}$ espaçamento utilizado foi de $1 \mathrm{~m}$ entre plantas e 1,5 m entre fileiras. A adubação de plantio consistiu na aplicação de um kg de composto orgânico (esterco curtido de gado), $400 \mathrm{~g}$ do fertilizante Yoorin (Mitsui Fertilizantes, Brasil) e $50 \mathrm{~g}$ de NPK (08-20-20) por cova. A adubação de cobertura consistiu de dez g de uréia por cova até o início do florescimento.

\section{DETERMINAÇÃO DOS COMPONENTES FÍSICO-QUÍMICOS DOS FRUTOS}

Procedeu-se a coleta manual de frutos de ambas as variedades no estádio verde-maduro (frutos completamente crescidos, com cor verde), acondicionados em bandejas e transportados para o Laboratório de Biotecnologia, da Universidade Paranaense, Toledo, PR, onde foram lavados em água corrente e, em seguida, em solução de hipoclorito de sódio ( $0,5 \%$ de cloro ativo). Posteriormente, realizaramse três lavagens com água destilada. Em seguida, os frutos foram submetidos à pulverização até o completo molhamento com água destilada (controle) ou com Etefon $\left(1000 \mathrm{mg} \mathrm{L}^{-1}\right)$, utilizado na forma do produto comercial Ethrel ${ }^{\Phi}$ (RhônePoulenc Ag Co, USA). Após a secagem sobre papel toalha, os frutos foram colocados sobre as bancadas do laboratório, para que pudessem amadurecer em temperatura média de $24 \pm 3^{\circ} \mathrm{C}$.

Em intervalos de três dias durante 12 dias de armazenamento foram realizadas avaliaçóes da firmeza do pericarpo e das características químicas da polpa como $\mathrm{pH}$, teor de sólidos solúveis totais (SST), acidez total titulável (ATT), razão SST/ ATT, umidade e cinzas.

A firmeza foi estimada pelo amaciamento do pericarpo, em um ponto da região mediana de cada fruto, utilizando- 
se a técnica não destrutiva de aplanaçáo, descrita por Calbo e Nery (1995). Os dados obtidos foram transformados em unidades de força $(\mathrm{MPa})$.

$\mathrm{O}$ teor de SST (expresso em ${ }^{\circ}$ Brix) e o $\mathrm{pH}$ foram determinados por leitura direta em soluçóes de polpa homogeneizada, em um refratômetro (Atago, EUA) e em um potenciômetro (Alpax, Brasil) previamente calibrado com os padróes $4 \mathrm{e} 7$, respectivamente. A ATT foi determinada em dez g da polpa trituradas com $90 \mathrm{~mL}$ de água destilada, tituladas rapidamente e sob agitação com solução de $0,01 \mathrm{~N}$ de $\mathrm{NaOH}$, utilizando a fenolftaleína $1 \%$ como indicador. Os resultados foram expressos em $\mathrm{g}$ de ácido cítrico por $100 \mathrm{~g}$ de amostra.

O teor de umidade da polpa (\%) foi determinado por meio da perda de massa da amostra aquecida a $105 \pm 1$ ${ }^{\circ} \mathrm{C}$, até a massa tornar-se constante. Estas amostras foram incineradas em mufla (Quimis, Brasil) a $550{ }^{\circ} \mathrm{C}$ e utilizadas na determinação do teor de cinzas (\% de resíduo mineral fixo). As análises da ATT, razão SST/ATT, umidade e cinzas foram realizadas segundo metodologia da AOAC (1990).

\section{DETERMINAÇÃO DA ATIVIDADE RESPIRATÓRIA E DA PRODUÇÃO DE ETILENO}

Foram coletados frutos de cubiu das variedades Santa Luzia e Thais no estádio verde-maduro, os quais foram acondicionados em caixas e transportados até o Laboratório de Pós-colheita do Departamento de Fitotecnia da Universidade Federal de Viçosa, Viçosa, MG. Os frutos foram lavados em água corrente e, após, com soluçáo de hipoclorito de sódio ( $0,5 \%$ de cloro ativo) seguida da tríplice lavagem com água destilada. Os mesmos permaneceram sobre as bancadas do laboratório durante uma hora para secagem e, em seguida, foram submetidos a pulverizaçáo até o completo molhamento com Etefon (1000 mg L-1 ) e o controle com água. Após a secagem, os frutos permaneceram à temperatura de $24{ }^{\circ} \mathrm{C}$ para o acompanhamento do amadurecimento.

Foram realizadas análises de perda de matéria fresca e evolução da cor, a cada três dias, durante 12 dias, sempre no mesmo grupo de frutos. A perda da matéria fresca foi avaliada pesando-se cada fruto em balança semi-analítica. Os resultados foram expressos em porcentagem, considerando-se a diferença entre a massa inicial e o obtido a cada intervalo de tempo de amostragem.

A evolução da cor da casca durante o amadurecimento foi avaliada seguindo a metodologia de McGuire (1992). Para isso, foi utilizado colorímetro (sistema L*, $\mathrm{a}^{*}, \mathrm{~b}^{*}$ ) Minolta modelo CR-300 (EUA), realizando-se três leituras por fruto, em diferentes pontos da região equatorial, a partir dos parâmetros luminosidade, cromaticidade e cor da casca $\left(\mathrm{H}^{\circ}\right)$.

A atividade respiratória e a produção de etileno foram determinadas a cada 24 horas, durante 12 dias. A atividade respiratória foi determinada pela quantificação da produção de
$\mathrm{CO}_{2}$ dos frutos. Os frutos foram colocados, individualmente, em frascos hermeticamente fechados com capacidade de $590 \mathrm{~mL}$. Após 30 e 90 minutos, respectivamente, foram retiradas amostras de $1 \mathrm{~mL}$ da atmosfera interna dos frascos com o auxílio de seringa, para a quantificaçáo do $\mathrm{CO}_{2} \mathrm{e}$ etileno liberados. As amostras foram injetadas em aparelho de cromatografia gasosa com coluna Porapak Q (Shimadzu GC-14B, Japão) de 1,60 m de comprimento. As temperaturas da coluna e do injetor foram $50^{\circ} \mathrm{C} \mathrm{e} 100^{\circ} \mathrm{C}$, respectivamente. Para análise de $\mathrm{CO}_{2}$, foi utilizado detector de condutividade térmica a $140{ }^{\circ} \mathrm{C}$ e corrente de $85 \mathrm{~A}$. A detecção de etileno foi realizada por detector de ionizaçáo de chama a $150{ }^{\circ} \mathrm{C}$. A taxa respiratória foi expressa em mg de $\mathrm{CO}_{2} \mathrm{~kg}^{-1} \mathrm{~h}^{-1}$ e a taxa de liberaçáo de etileno em $\mu \mathrm{L} \mathrm{kg}^{-1} \mathrm{~h}^{-1}$.

\section{ANÁLISE ESTATÍSTICA}

Para a avaliação das características físico-químicas foi utilizado o delineamento inteiramente casualizado, no esquema fatorial $2 \times 2 \times 5$ (duas variedades, duas concentraçóes de Etefon e cinco períodos de avaliaçáo), portanto, com 20 tratamentos. A unidade experimental foi composta por três frutos de cada variedade, os quais constituíram a unidade experimental. Os dados foram submetidos à análise de variância e de regressão.

Para a análise da atividade respiratória e produção de etileno, foi utilizado o delineamento inteiramente casualizado em parcelas subdivididas com esquema fatorial na parcela (combinaçóes de variedade e Etefon) e na subparcela o fator tempo, com três repetiçôes. A unidade experimental constou de três frutos para cada combinação de tratamento. Os dados foram submetidos à análise de variância. Não foram possíveis os ajustes de modelos matemáticos para estabelecer uma relação funcional entre as variáveis dependentes (etileno e $\mathrm{CO}_{2}$ ) e a variável independente (dias após a colheita). Dessa forma, optou-se pela estatística descritiva e desvio padrão. Todas as análises foram efetuadas com auxílio do programa computacional SISVAR (Ferreira 2000).

\section{RESULTADOS E DISCUSSÃO}

Foram encontradas diferenças significativas para a interação variedades, concentração de Etefon e tempo de armazenamento para todas as variáveis-resposta e todos os desdobramentos foram realizados.

Ocorreu perda de firmeza do pericarpo dos frutos de cubiu em função do avanço do tempo de armazenamento pós-colheita, de forma exponencial, em todas as combinaçóes de variedades e concentraçóes de Etefon sendo mais acentuada nos três primeiros dias (Figura 1A), diferindo entre as variedades na primeira avaliação (Tabela 1), sem interferência da aplicação do Etefon (Tabela 2). 

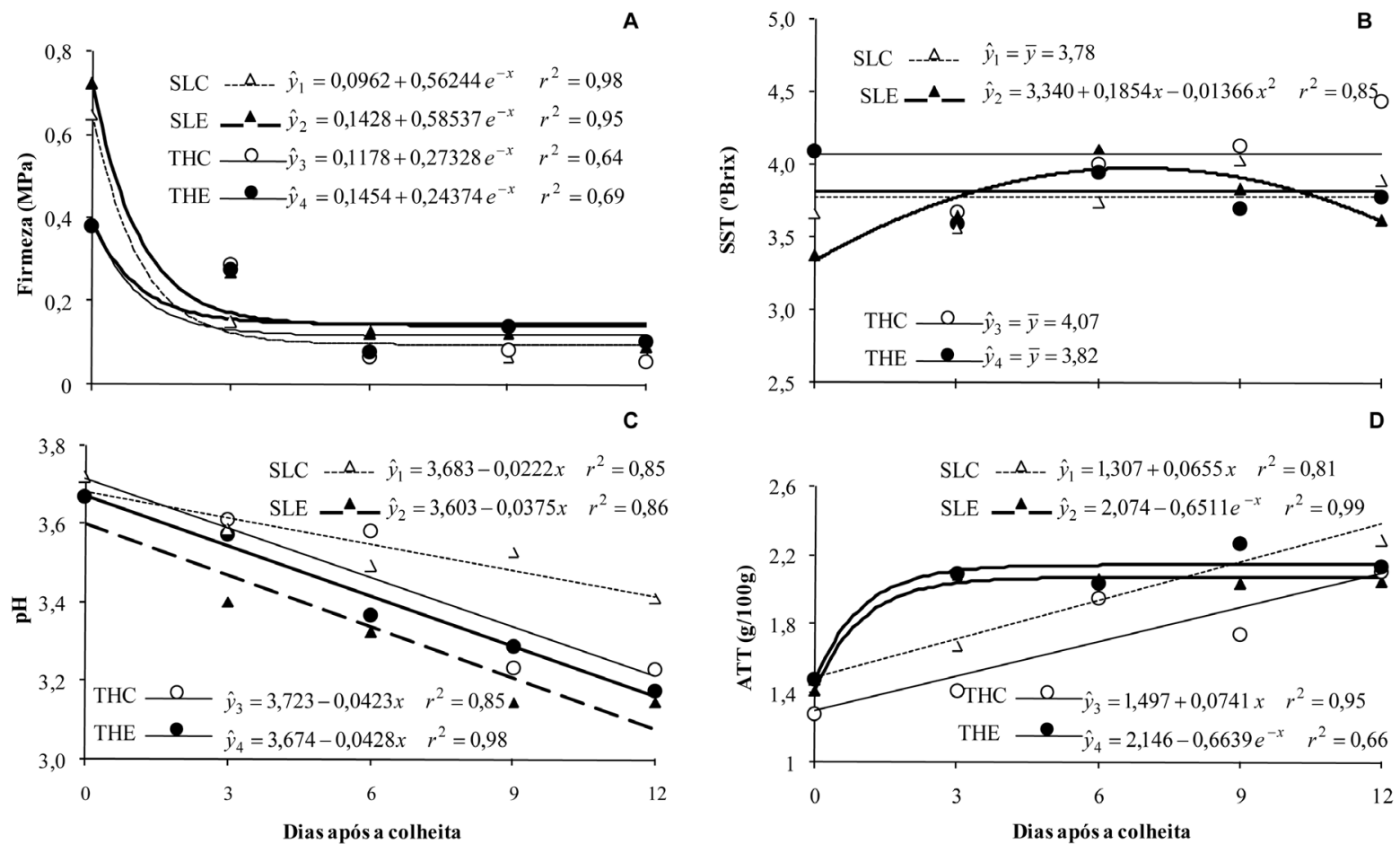

Figura 1 - Características físico-químicas de frutos de cubiu durante 0 armazenamento por 12 dias. A) Firmeza do pericarpo; B) Teor de Sólidos Solúveis Totais (SST); C) Valor do pH; D) Acidez Total Titulável (ATT). SLC = Santa Luzia controle; SLE = Santa Luzia com Etefon (1000 mg L-1); THC = Thais controle; THE $=$ Thais com Etefon $\left(1000 \mathrm{mg} \mathrm{L}^{-1}\right)$.

O declínio da firmeza tem sido atribuído principalmente, a hidrólise de polissacarídeos da parede celular e a degradação enzimática de componentes pécticos da lamela média (Chitarra e Chitarra 2005). Em trabalhos realizados por Hernández et al. (2004), por outro lado, não foram observadas alteraçôes marcantes na firmeza dos frutos de cubiu ao longo de 25 dias de armazenamento, porém os mesmos foram mantidos a 15 ${ }^{\circ} \mathrm{C}$ e com $80 \%$ de umidade relativa.

Os teores de SST não variaram em função do tempo de armazenamento pós-colheita, exceto nos frutos da variedade Santa Luzia tratados com Etefon, os quais tiveram pequena variação na forma de uma curva quadrática (Figura 1B), sendo verificadas diferenças significativas entre as variedades apenas no tempo zero (Tabela 1) e com a aplicaçáo de Etefon apenas no $12^{\circ}$ dia de armazenamento (Tabela 2), onde os frutos náo tratados apresentaram os maiores valores médios de SST ( $4,43^{\circ}$ Brix).

Os valores médios dos SST foram inferiores aos obtidos em outros trabalhos com frutos de cubiu, entretanto, vale lembrar que nesse trabalho o amadurecimento aconteceu fora da planta-mãe. Silva Filho et al. (1989) analisaram doze introduçôes de cubiu provenientes de diferentes partes da Amazônia e cultivadas em Manaus, e encontraram frutos com
4,5 a 6 Brix. Em torno de $70 \%$ das plantas de populaçóes naturais de cubiu da Amazônia cultivadas no Estado de Pernambuco por Silva Filho et al. (1996) apresentaram 6 oBrix. Os autores sugerem que as condiçóes ambientais onde foi conduzido o experimento favoreceram a expressão de genes que controlam este caráter.

Hernández et al. (2004) relataram que frutos de cubiu cultivados na Amazônia Colombiana e armazenados a $15^{\circ} \mathrm{C}$ apresentaram oscilaçóes nos SST ao longo de 24 dias de armazenamento. Segundo os autores, em frutos não-climatéricos como o cubiu, os açúcares, principais componentes dos SST, são derivados principalmente de substâncias assimiladas e não de reservas amiláceas, conforme ocorre em frutos climatéricos, onde o teor de SST aumenta com o avanço do tempo de armazenamento.

Domingues et al. (2001) verificaram que a imersão de frutos não-climatéricos como os de laranja (Citrus sinensis L. Osbeck.) cultivar "Baianinha" por cinco minutos em solução contendo $1000 \mathrm{mg} \mathrm{L}^{-1}$ de Etefon não proporcionou aumento significativo no teor de SST. De modo similar, Santana et al. (2004) náo evidenciaram efeito significativo da imersão rápida (dez minutos) dos frutos de abacaxi 'Pérola' (Ananas comosus L. Merr.) em solução com 1000 
Tabela 1 - Valores médios para as características firmeza do pericarpo (FP), sólidos solúveis totais (SST), pH, acidez total titulável (ATT), relação SST/ATT $(\mathrm{S} / \mathrm{A})$, umidade $(\mathrm{Um})$, cinzas $(\mathrm{Cz})$, perda de matéria fresca $(\mathrm{PMF})$, luminosidade $(\mathrm{L})$, cromaticidade $(\mathrm{C})$ e ângulo de cor $\left(\mathrm{H}^{\circ}\right)$, das variedades Santa Luzia $(\mathrm{SL})$ e Thais (TH) em função do tempo (0, 3, 6, 9 e 12 dias) e Etefon (0 e $\left.1000 \mathrm{mg} \mathrm{L}^{-1}\right)$.

\begin{tabular}{|c|c|c|c|c|c|c|c|c|c|c|c|}
\hline \multirow{3}{*}{ Caráter } & \multirow{3}{*}{ Variedade } & \multicolumn{10}{|c|}{ Dias após a colheita } \\
\hline & & \multicolumn{2}{|c|}{0} & \multicolumn{2}{|c|}{3} & \multicolumn{2}{|c|}{6} & \multicolumn{2}{|c|}{9} & \multicolumn{2}{|c|}{12} \\
\hline & & 0 & 1000 & 0 & 1000 & 0 & 1000 & 0 & 1000 & 0 & 1000 \\
\hline FP & SL & $0,66 \mathrm{a}$ & $0,72 \mathrm{a}$ & $0,15 \mathrm{a}$ & $0,27 \mathrm{a}$ & $0,13 a$ & $0,12 \mathrm{a}$ & $0,06 \mathrm{a}$ & $0,12 \mathrm{a}$ & $0,07 \mathrm{a}$ & $0,09 \mathrm{a}$ \\
\hline (MPa) & TH & $0,38 \mathrm{~b}$ & $0,38 b$ & $0,29 a$ & $0,28 \mathrm{a}$ & $0,06 \mathrm{a}$ & $0,08 \mathrm{a}$ & $0,08 \mathrm{a}$ & $0,14 \mathrm{a}$ & $0,05 \mathrm{a}$ & $0,10 \mathrm{a}$ \\
\hline SST & SL & $3,68 \mathrm{a}$ & $3,38 b$ & $3,57 \mathrm{a}$ & $3,65 \mathrm{a}$ & $3,74 \mathrm{a}$ & $4,11 \mathrm{a}$ & $4,03 \mathrm{a}$ & $3,83 \mathrm{a}$ & $3,89 \mathrm{a}$ & $3,62 \mathrm{a}$ \\
\hline ( ${ }^{\circ} B$ rix) & TH & $4,10 \mathrm{a}$ & $4,10 \mathrm{a}$ & $3,68 \mathrm{a}$ & $3,60 \mathrm{a}$ & $4,01 \mathrm{a}$ & $3,94 \mathrm{a}$ & $4,13 \mathrm{a}$ & $3,70 \mathrm{a}$ & $4,43 \mathrm{a}$ & $3,78 \mathrm{a}$ \\
\hline \multirow[t]{2}{*}{$\mathrm{pH}$} & SL & $3,72 \mathrm{a}$ & $3,68 \mathrm{a}$ & $3,59 \mathrm{a}$ & $3,40 \mathrm{a}$ & $3,49 a$ & $3,33 \mathrm{a}$ & $3,53 \mathrm{a}$ & $3,34 \mathrm{a}$ & $3,41 \mathrm{a}$ & $3,15 \mathrm{a}$ \\
\hline & TH & $3,68 \mathrm{a}$ & $3,68 \mathrm{a}$ & $3,61 \mathrm{a}$ & $3,57 \mathrm{a}$ & $3,59 a$ & $3,37 \mathrm{a}$ & $3,24 \mathrm{~b}$ & $3,29 \mathrm{a}$ & $3,23 \mathrm{a}$ & $3,18 \mathrm{a}$ \\
\hline ATT & SL & $1,29 \mathrm{a}$ & $1,42 \mathrm{a}$ & $1,42 \mathrm{a}$ & $2,09 \mathrm{a}$ & $1,95 \mathrm{a}$ & $2,07 \mathrm{a}$ & $1,75 b$ & $2,05 \mathrm{a}$ & $2,11 \mathrm{a}$ & $2,05 \mathrm{a}$ \\
\hline$(\mathrm{g} / 100 \mathrm{~g})$ & TH & $1,48 \mathrm{a}$ & $1,48 \mathrm{a}$ & $1,68 \mathrm{a}$ & $2,10 \mathrm{a}$ & $1,97 \mathrm{a}$ & $2,04 \mathrm{a}$ & $2,28 \mathrm{a}$ & $2,27 \mathrm{a}$ & $2,29 a$ & $2,14 \mathrm{a}$ \\
\hline \multirow[t]{2}{*}{$S / A$} & SL & $3,24 \mathrm{a}$ & $2,50 \mathrm{a}$ & $2,82 \mathrm{a}$ & $1,92 \mathrm{a}$ & $1,93 a$ & $1,99 a$ & $2,40 \mathrm{a}$ & $1,89 a$ & $1,92 \mathrm{a}$ & $1,80 \mathrm{a}$ \\
\hline & TH & $3,22 \mathrm{a}$ & $3,22 \mathrm{a}$ & $2,52 \mathrm{a}$ & $1,89 a$ & $2,25 \mathrm{a}$ & $1,98 \mathrm{a}$ & $1,82 \mathrm{a}$ & $1,68 \mathrm{a}$ & $1,96 \mathrm{a}$ & $1,81 \mathrm{a}$ \\
\hline Um & SL & $92,18 \mathrm{a}$ & $93,03 \mathrm{a}$ & $91,35 \mathrm{a}$ & $91,57 \mathrm{a}$ & $91,44 \mathrm{a}$ & $90,55 \mathrm{a}$ & $91,25 \mathrm{a}$ & $91,22 \mathrm{a}$ & $91,71 \mathrm{a}$ & $90,96 \mathrm{a}$ \\
\hline (\%) & TH & $90,35 \mathrm{a}$ & $90,35 \mathrm{a}$ & 90,39 a & $91,11 \mathrm{a}$ & $91,19 a$ & $90,16 \mathrm{a}$ & $90,79 a$ & 90,94 a & $90,82 \mathrm{a}$ & $90,56 \mathrm{a}$ \\
\hline $\mathrm{Cz}$ & SL & $1,78 \mathrm{a}$ & $1,59 \mathrm{a}$ & $1,62 \mathrm{a}$ & $1,56 \mathrm{a}$ & $1,44 \mathrm{a}$ & $1,51 \mathrm{a}$ & $1,61 \mathrm{a}$ & $1,37 \mathrm{a}$ & $1,83 \mathrm{a}$ & $1,16 \mathrm{a}$ \\
\hline$(\%)$ & TH & $2,01 \mathrm{a}$ & $2,01 \mathrm{a}$ & $1,52 \mathrm{a}$ & $1,88 \mathrm{a}$ & $1,51 \mathrm{a}$ & $1,73 \mathrm{a}$ & $1,38 \mathrm{a}$ & $1,42 \mathrm{a}$ & $1,51 \mathrm{a}$ & $1,67 \mathrm{a}$ \\
\hline PMF & SL & $0 \mathrm{a}$ & $0 \mathrm{a}$ & $2,28 \mathrm{a}$ & $2,63 \mathrm{a}$ & $4,10 \mathrm{a}$ & $4,66 \mathrm{a}$ & $5,40 \mathrm{a}$ & $7,40 \mathrm{a}$ & $7,20 \mathrm{a}$ & $11,1 \mathrm{a}$ \\
\hline$(\%)$ & TH & $0 \mathrm{a}$ & $0 \mathrm{a}$ & $3,38 \mathrm{a}$ & $2,31 \mathrm{a}$ & $4,03 \mathrm{a}$ & $4,30 \mathrm{a}$ & $5,87 \mathrm{a}$ & $6,28 \mathrm{a}$ & $7,83 \mathrm{a}$ & $8,12 \mathrm{a}$ \\
\hline \multirow[t]{2}{*}{ L } & SL & 39,37 a & $41,70 \mathrm{a}$ & $41,72 \mathrm{a}$ & $47,51 \mathrm{a}$ & $43,28 a$ & $56,80 \mathrm{a}$ & $48,52 \mathrm{a}$ & $60,40 \mathrm{a}$ & $55,1 \mathrm{a}$ & $62,14 \mathrm{a}$ \\
\hline & TH & $38,55 \mathrm{a}$ & $38,25 a$ & $40,79 a$ & $42,49 \mathrm{~b}$ & $46,18 \mathrm{a}$ & 49,09 b & $50,60 \mathrm{a}$ & $53,72 \mathrm{~b}$ & $55,96 \mathrm{a}$ & $57,87 \mathrm{a}$ \\
\hline \multirow[t]{2}{*}{ C } & SL & $25,7 \mathrm{a}$ & $28,96 \mathrm{a}$ & $28,5 \mathrm{a}$ & $37,29 \mathrm{a}$ & $32,4 \mathrm{a}$ & $54,22 \mathrm{a}$ & $41,8 \mathrm{a}$ & $63,49 a$ & $55,1 \mathrm{a}$ & $66,78 \mathrm{a}$ \\
\hline & TH & $24,17 \mathrm{a}$ & $24,8 \mathrm{a}$ & $30,07 \mathrm{a}$ & $26,8 \mathrm{a}$ & $44,66 \mathrm{a}$ & $36,4 \mathrm{~b}$ & $53,79 a$ & $46,1 \mathrm{~b}$ & $63,85 \mathrm{a}$ & $57,6 \mathrm{a}$ \\
\hline \multirow[t]{2}{*}{$\mathrm{H}^{0}$} & SL & $112 \mathrm{a}$ & $112,6 \mathrm{a}$ & $111,7 \mathrm{a}$ & $105 \mathrm{a}$ & $103,3 \mathrm{a}$ & $86,74 \mathrm{a}$ & $92,75 \mathrm{a}$ & $76,49 a$ & $80,47 \mathrm{a}$ & $75,38 \mathrm{a}$ \\
\hline & TH & $109,4 \mathrm{a}$ & $112,8 \mathrm{a}$ & $110,4 \mathrm{a}$ & $105,7 \mathrm{a}$ & $98,9 \mathrm{a}$ & $89,00 \mathrm{a}$ & $86,07 \mathrm{a}$ & $79,13 \mathrm{a}$ & $74,35 \mathrm{a}$ & $68,30 \mathrm{a}$ \\
\hline
\end{tabular}

Médias seguidas da mesma letra, na coluna, comparando as variedades, para cada combinação de tempo e de Etefon, não diferem entre si pelo teste $\mathrm{F}$ a $5 \%$ de probabilidade.

Tabela 2 - Valores médios para as características firmeza do pericarpo (FP), sólidos solúveis totais (SST), pH, acidez total titulável (ATT), relação SST/ATT $(\mathrm{S} / \mathrm{A})$, umidade $(\mathrm{Um})$, cinzas $(\mathrm{tCz})$, perda de matéria fresca (PMF), luminosidade $(\mathrm{L})$, cromaticidade $(\mathrm{C})$ e ângulo de cor $\left(\mathrm{H}^{\circ}\right)$, de acordo 0 Etefon $(0$ e 1000 $\mathrm{mg} \mathrm{L}^{-1}$ ) em função das variedades Santa Luzia (SL) e Thais (TH) e do tempo (0, 3, 6, 9 e 12 dias).

\begin{tabular}{|c|c|c|c|c|c|c|c|c|c|c|c|}
\hline \multirow[t]{3}{*}{ Caráter } & \multirow[t]{3}{*}{$\begin{array}{l}\text { Etefon } \\
\left(\mathrm{mgL}^{-1}\right)\end{array}$} & \multicolumn{10}{|c|}{ Dias após a colheita } \\
\hline & & \multicolumn{2}{|c|}{0} & \multicolumn{2}{|c|}{3} & \multicolumn{2}{|c|}{6} & \multicolumn{2}{|c|}{9} & \multicolumn{2}{|c|}{12} \\
\hline & & SL & TH & SL & TH & SL & TH & SL & TH & SL & TH \\
\hline FP & 0 & $0,66 \mathrm{a}$ & $0,38 \mathrm{a}$ & $0,15 \mathrm{a}$ & $0,29 \mathrm{a}$ & $0,13 a$ & $0,06 \mathrm{a}$ & $0,06 \mathrm{a}$ & $0,08 \mathrm{a}$ & $0,07 \mathrm{a}$ & $0,05 \mathrm{a}$ \\
\hline (MPa) & 1000 & $0,72 \mathrm{a}$ & $0,38 \mathrm{a}$ & $0,27 \mathrm{a}$ & $0,28 \mathrm{a}$ & $0,12 \mathrm{a}$ & $0,08 \mathrm{a}$ & $0,12 \mathrm{a}$ & $0,14 \mathrm{a}$ & $0,09 \mathrm{a}$ & $0,10 \mathrm{a}$ \\
\hline SST & 0 & $3,68 \mathrm{a}$ & $4,10 \mathrm{a}$ & $3,57 \mathrm{a}$ & $3,68 \mathrm{a}$ & $3,74 \mathrm{a}$ & $4,01 \mathrm{a}$ & $4,03 \mathrm{a}$ & $4,13 \mathrm{a}$ & $3,89 a$ & $4,43 \mathrm{a}$ \\
\hline ( ${ }^{\circ}$ Brix) & 1000 & $3,38 \mathrm{a}$ & $4,10 \mathrm{a}$ & $3,65 \mathrm{a}$ & $3,60 \mathrm{a}$ & $4,11 \mathrm{a}$ & 3,94 a & $3,83 \mathrm{a}$ & $3,70 \mathrm{a}$ & $3,62 \mathrm{a}$ & $3,78 \mathrm{~b}$ \\
\hline \multirow[t]{2}{*}{$\mathrm{pH}$} & 0 & $3,72 \mathrm{a}$ & $3,68 \mathrm{a}$ & $3,59 \mathrm{a}$ & $3,61 \mathrm{a}$ & $3,49 a$ & $3,59 \mathrm{a}$ & $3,53 \mathrm{a}$ & $3,24 \mathrm{a}$ & $3,41 \mathrm{a}$ & $3,23 \mathrm{a}$ \\
\hline & 1000 & $3,68 \mathrm{a}$ & $3,68 \mathrm{a}$ & $3,40 \mathrm{a}$ & $3,57 \mathrm{a}$ & $3,33 \mathrm{a}$ & 3,37 a & $3,34 \mathrm{a}$ & $3,29 \mathrm{a}$ & $3,15 \mathrm{a}$ & $3,18 \mathrm{a}$ \\
\hline ATT & 0 & $1,29 a$ & $1,48 \mathrm{a}$ & $1,48 \mathrm{~b}$ & $1,68 \mathrm{a}$ & $1,95 \mathrm{a}$ & $1,97 \mathrm{a}$ & $1,75 \mathrm{a}$ & $2,28 \mathrm{a}$ & $2,11 \mathrm{a}$ & $2,29 \mathrm{a}$ \\
\hline$(\mathrm{g} / 100 \mathrm{~g})$ & 1000 & $1,42 \mathrm{a}$ & $1,48 \mathrm{a}$ & $2,09 \mathrm{a}$ & $2,10 \mathrm{a}$ & $2,07 \mathrm{a}$ & $2,04 \mathrm{a}$ & $2,05 \mathrm{a}$ & $2,27 \mathrm{a}$ & $2,05 \mathrm{a}$ & $2,14 \mathrm{a}$ \\
\hline \multirow[t]{2}{*}{$S / A$} & 0 & $3,24 \mathrm{a}$ & $3,22 \mathrm{a}$ & 2,82 a & $2,52 \mathrm{a}$ & $1,93 \mathrm{a}$ & $2,25 \mathrm{a}$ & $2,40 \mathrm{a}$ & $1,82 \mathrm{a}$ & $1,92 \mathrm{a}$ & $1,96 \mathrm{a}$ \\
\hline & 1000 & $2,50 \mathrm{a}$ & $3,22 \mathrm{a}$ & $1,92 \mathrm{~b}$ & $1,89 \mathrm{a}$ & $1,99 a$ & $1,98 \mathrm{a}$ & $1,89 a$ & $1,68 \mathrm{a}$ & $1,80 \mathrm{a}$ & $1,81 \mathrm{a}$ \\
\hline Um & 0 & $92,18 \mathrm{a}$ & $90,35 \mathrm{a}$ & $91,35 \mathrm{a}$ & $90,39 a$ & $91,44 \mathrm{a}$ & $91,19 a$ & $91,25 \mathrm{a}$ & $90,79 a$ & $91,71 \mathrm{a}$ & $90,82 \mathrm{a}$ \\
\hline (\%) & 1000 & $93,03 \mathrm{a}$ & $90,35 \mathrm{a}$ & $91,57 \mathrm{a}$ & $91,11 \mathrm{a}$ & $90,55 \mathrm{a}$ & $90,16 \mathrm{a}$ & $91,22 \mathrm{a}$ & $90,94 \mathrm{a}$ & $90,96 \mathrm{a}$ & $90,56 \mathrm{a}$ \\
\hline $\mathrm{Cz}$ & 0 & $1,78 \mathrm{a}$ & $2,01 \mathrm{a}$ & $1,62 \mathrm{a}$ & $1,52 \mathrm{a}$ & $1,44 \mathrm{a}$ & $1,51 \mathrm{a}$ & $1,61 \mathrm{a}$ & $1,38 \mathrm{a}$ & $1,83 \mathrm{a}$ & $1,51 \mathrm{a}$ \\
\hline (\%) & 1000 & $1,59 a$ & $2,01 \mathrm{a}$ & $1,56 \mathrm{a}$ & $1,88 \mathrm{a}$ & $1,51 \mathrm{a}$ & $1,73 \mathrm{a}$ & $1,37 \mathrm{a}$ & $1,42 \mathrm{a}$ & $1,16 b$ & $1,67 \mathrm{a}$ \\
\hline
\end{tabular}


Tabela 2 - Continuação.

\begin{tabular}{|c|c|c|c|c|c|c|c|c|c|c|c|}
\hline \multirow{3}{*}{$\begin{array}{c}\text { Caráter } \\
\text { PMF }\end{array}$} & \multirow{3}{*}{$\begin{array}{c}\begin{array}{c}\text { Etefon } \\
\left(\mathrm{mgL}^{-1}\right)\end{array} \\
\\
0\end{array}$} & \multicolumn{10}{|c|}{ Dias após a colheita } \\
\hline & & \multicolumn{2}{|c|}{0} & \multicolumn{2}{|c|}{3} & \multicolumn{2}{|c|}{6} & \multicolumn{2}{|c|}{9} & \multicolumn{2}{|c|}{12} \\
\hline & & $0 \mathrm{a}$ & $0 \mathrm{a}$ & $2,28 \mathrm{a}$ & $3,38 \mathrm{a}$ & $4,10 \mathrm{a}$ & $4,03 \mathrm{a}$ & $5,40 \mathrm{a}$ & $5,87 \mathrm{a}$ & $7,20 \mathrm{a}$ & $7,83 \mathrm{a}$ \\
\hline (\%) & 1000 & $0 \mathrm{a}$ & $0 \mathrm{a}$ & 2,63 a & $2,31 \mathrm{a}$ & $4,66 \mathrm{a}$ & $4,30 \mathrm{a}$ & $7,40 \mathrm{a}$ & $6,28 \mathrm{a}$ & $11,1 \mathrm{~b}$ & $8,12 \mathrm{a}$ \\
\hline \multirow[t]{2}{*}{ L } & 0 & $39,37 \mathrm{a}$ & $38,55 \mathrm{a}$ & 41,72 b & $40,79 a$ & $43,28 \mathrm{~b}$ & $46,18 \mathrm{a}$ & $48,52 \mathrm{~b}$ & $50,60 \mathrm{a}$ & $55,1 \mathrm{~b}$ & $55,96 \mathrm{a}$ \\
\hline & 1000 & $41,70 \mathrm{a}$ & $38,25 a$ & $47,51 \mathrm{a}$ & $42,49 a$ & $56,80 \mathrm{a}$ & $49,09 \mathrm{a}$ & $60,40 \mathrm{a}$ & $53,72 \mathrm{a}$ & $62,14 \mathrm{a}$ & $57,87 \mathrm{a}$ \\
\hline \multirow[t]{2}{*}{ C } & 0 & $25,7 \mathrm{a}$ & $24,8 \mathrm{a}$ & $28,5 \mathrm{~b}$ & $26,8 \mathrm{a}$ & $32,4 \mathrm{~b}$ & $36,4 \mathrm{~b}$ & $41,8 \mathrm{~b}$ & $46,1 \mathrm{a}$ & $55,1 \mathrm{~b}$ & $57,6 \mathrm{a}$ \\
\hline & 1000 & $28,96 \mathrm{a}$ & $24,17 \mathrm{a}$ & $37,29 a$ & $30,07 \mathrm{a}$ & $54,22 \mathrm{a}$ & $44,66 \mathrm{a}$ & $63,49 a$ & $53,79 a$ & $66,78 \mathrm{a}$ & $63,85 \mathrm{a}$ \\
\hline \multirow[t]{2}{*}{$\mathrm{H}^{0}$} & 0 & $112 \mathrm{a}$ & $109,4 \mathrm{a}$ & $111,7 \mathrm{~b}$ & $110,4 \mathrm{a}$ & $103,3 \mathrm{~b}$ & $98,9 \mathrm{~b}$ & $92,75 \mathrm{a}$ & $86,07 \mathrm{a}$ & $80,47 \mathrm{a}$ & $74,35 \mathrm{a}$ \\
\hline & 1000 & $112,6 \mathrm{a}$ & $112,8 \mathrm{a}$ & $105 \mathrm{a}$ & $105,7 \mathrm{a}$ & $86,74 \mathrm{a}$ & $89,00 \mathrm{a}$ & $76,49 a$ & $79,13 \mathrm{a}$ & $75,38 \mathrm{a}$ & $68,3 \mathrm{a}$ \\
\hline
\end{tabular}

Médias seguidas da mesma letra, na coluna, comparando os tratamentos com Etefon, para cada combinação de tempo e variedade, não diferem entre si pelo teste $\mathrm{F}$ a $5 \%$ de probabilidade.

$\mathrm{mg} \mathrm{L}^{-1}$ de Etefon no teor de SST. Frutos náo-climatéricos de Solanum muricatum Ait. apresentaram aumento no teor de SST durante o amadurecimento dos frutos na planta, entretanto, quando o amadurecimento ocorreu fora da planta, alteraçôes relativamente pequenas foram observadas (Ahumada e Cantwell 1996). Por outro lado, Oliveira Júnior et al. (2004) analisando as alteraçôes pós-colheita da fruta-delobo (Solanum lycocarpum St. Hil.) durante o amadurecimento verificaram aumento do teor de SST ao longo de 20 dias de armazenamento em temperatura média de $22^{\circ} \mathrm{C}$.

$\mathrm{O} \mathrm{pH}$ apresentou decréscimo linear em funçáo do tempo após a colheita em todas as combinaçôes de variedades e de Etefon (Figura 1C), enquanto o teor médio de ATT apresentou acréscimo linear em ambas as variedades não tratadas com Etefon e acréscimo exponencial quando tratadas, sendo mais acentuado nos três primeiros dias (Figura 1D), com diferenças significativas entre as variedades somente no nono dia (Tabela 1) e da aplicaçáo de Etefon apenas no terceiro dia de armazenamento (Tabela 2).

A ATT dos frutos após 12 dias de armazenamento a temperatura ambiente, independentemente do tratamento ou náo com Etefon e da variedade, variou de 2,1 a 2,3 g de ácido cítrico/100 $\mathrm{g}$ do fruto. Estes valores foram superiores à média $(1,47)$ obtida por Silva Filho et al. (1999) em frutos de 24 etnovariedades da Amazônia brasileira, peruana e colombiana, coletados maduros, com coloração amarela e amadurecidos na planta. Segundo Silva Filho (2002) o cubiu é considerado um fruto ácido e a acidez elevada contribui para o sabor do fruto, permitindo um fator de diluição elevado na formulação de sucos e, conseqüentemente, contribuindo em seu rendimento industrial para esta finalidade.

Os resultados obtidos foram similares aos relatados por Hernández et al. (2004), os quais demonstraram que frutos de cubiu apresentaram aumento da ATT até o décimo dia de armazenamento a $15^{\circ} \mathrm{C}$, havendo após este período diminuiçáo da ATT e aumento do $\mathrm{pH}$ até o período de observaçáo de 25 dias. Apesar de ter ocorrido elevaçáo da acidez e diminuição do $\mathrm{pH}$ com a maturação, contrariando as observaçóes da maioria dos frutos, elas foram de pequena magnitude. Alterações pós-colheita similares foram observadas por Oliveira Júnior et al. (2004) durante o amadurecimento de frutos de fruta-de-lobo, onde a ATT aumentou e o $\mathrm{pH}$ diminuiu ao longo de 18 dias de armazenamento em temperatura média de $22^{\circ} \mathrm{C}$, sem o tratamento com Etefon.

Neres et al. (2004) observaram aumento linear do teor de ATT ao longo de 15 dias de armazenamento a $25^{\circ} \mathrm{C}$ de frutos de jiló (Solanum gilo Raddi), indicando que os ácidos orgânicos não são a principal fonte de energia, no período de observação, para a respiração durante o processo de maturaçáo, como pode ocorrer em alguns frutos. Lima et al. (2003) também observaram aumento linear da ATT e diminuição do $\mathrm{pH}$ de frutos de graviola (Annona muricata L.) colhidos na maturidade fisiológica e armazenados a $23,4^{\circ} \mathrm{C}$ por um período de seis dias. Os autores do trabalho atribuíram este acúmulo, possivelmente, a reduzida utilização dos ácidos orgânicos nas vias oxidativas normais.

A razão SST/ATT diminuiu de forma linear em função do tempo de armazenamento pós-colheita, exceto para a variedade Santa Luzia tratada com Etefon, a qual se manteve estável (Figura 2A), sem diferenças significativas entre as variedades e com o tratamento com Etefon apenas no terceiro dia de avaliação (Tabela 1 e 2). A diminuição na razáo SST/ ATT pode ser atribuída ao aumento da ATT ao longo do amadurecimento fora da planta. A relação brix/acidez (SST/ ATT) em frutos de cubiu é baixa, confirmando seu baixo grau de doçura e sua pequena utilização para o consumo in natura, conforme relatos de Silva Filho (2002).

Santana et al. (2004) relataram que frutos de abacaxi, embora não-climatéricos, apresentaram alterações relevantes nas suas propriedades químicas e físico-químicas na fase pós-colheita. A acidez da polpa aumentou com o avanço do período de armazenamento para frutos tratados com Etefon 
e frutos testemunha, resultando numa redução progressiva da relação SST/ATT.

A percentagem média de cinzas apresentou decréscimo linear em função do tempo de armazenamento, exceto em frutos da variedade Santa Luzia não tratados com Etefon (Figura $2 \mathrm{~B}$ ), enquanto a umidade não variou em função do tempo de armazenamento pós-colheita (Figura 2C), da variedade e do tratamento com Etefon (Tabela 1 e 2).

As variedades de cubiu analisadas apresentaram elevados teores de umidade, com variação de 90,2 a $93 \%$. Esses resultados evidenciaram que o fruto é suculento, corroborando com os estudos realizados por Silva Filho (2002) e Yuyama et al. (2007). As cinzas em alimentos referem-se ao resíduo inorgânico remanescente da queima da matéria orgânica e se tornam importantes quando há determinação dos minerais presentes nos frutos, o que não foi avaliado neste trabalho.

Houve aumento linear para a perda de matéria fresca em razáo do tempo de avaliação em todas as combinaçôes de variedades e de Etefon (Figura 2D), chegando a 11\% de perda a partir da massa inicial no $12^{\circ}$ dia de armazenamento com a aplicação de Etefon (Tabelas 1 e 2).

Hernández et al. (2004) relataram que frutos de cubiu armazenados a $15^{\circ} \mathrm{C}$ perderam entre 4 a $5 \%$ de sua massa inicial durante os primeiros 19 dias de armazenamento,
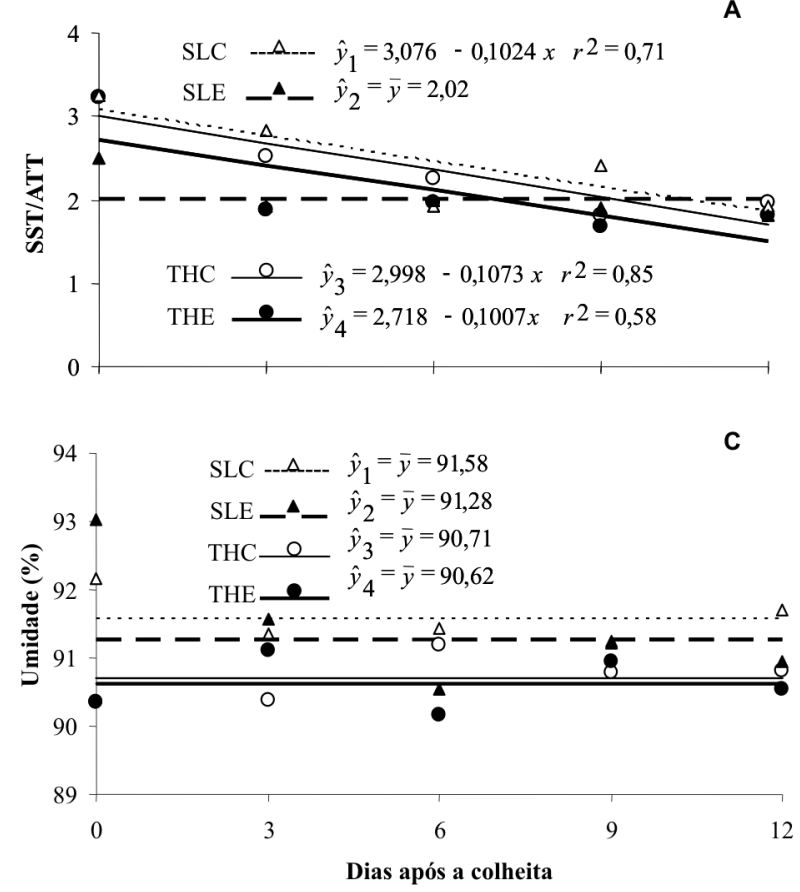

momento a partir do qual se observaram sintomas de desidratação e perda acelerada de massa e firmeza.

As análises da evolução da cor evidenciaram que a luminosidade (L) e a cromaticidade (C) aumentaram linearmente com o tempo de armazenamento em todas as combinaçôes de variedades e concentraçôes de Etefon (Figura $3 \mathrm{~A} \mathrm{e} 3 \mathrm{~B}$ ), sendo observadas diferenças entre as variedades entre o terceiro e o nono dia de observaçáo (Tabela 1). Maiores valores de L e C foram obtidos em frutos da variedade Santa Luzia tratados Etefon a partir do terceiro dia de observaçáo (Tabela 2), quando estavam com $50 \%$ da superfície do pericarpo amarela.

$\mathrm{O}$ ângulo de cor da casca $\left(\mathrm{H}^{\circ}\right)$ diminuiu de forma linear nos frutos em ambas variedades tratadas com Etefon. Entretanto, apresentou ajuste quadrático naqueles não tratados com Etefon durante o armazenamento pós-colheita (Figura 3C), sem diferenças entre as variedades (Tabela 1).

O tratamento com Etefon antecipou a mudança de coloraçấo dos frutos, a qual também ocorreu nos frutos não tratados mas de forma mais lenta. Os primeiros frutos a mudar de coloração foram os tratados com Etefon a partir do terceiro dia de armazenamento em ambas variedades, e após 12 dias de amadurecimento pós-colheita os frutos tratados com Etefon de ambas as variedades apresentaram coloraçáo amarelo-avermelhada.

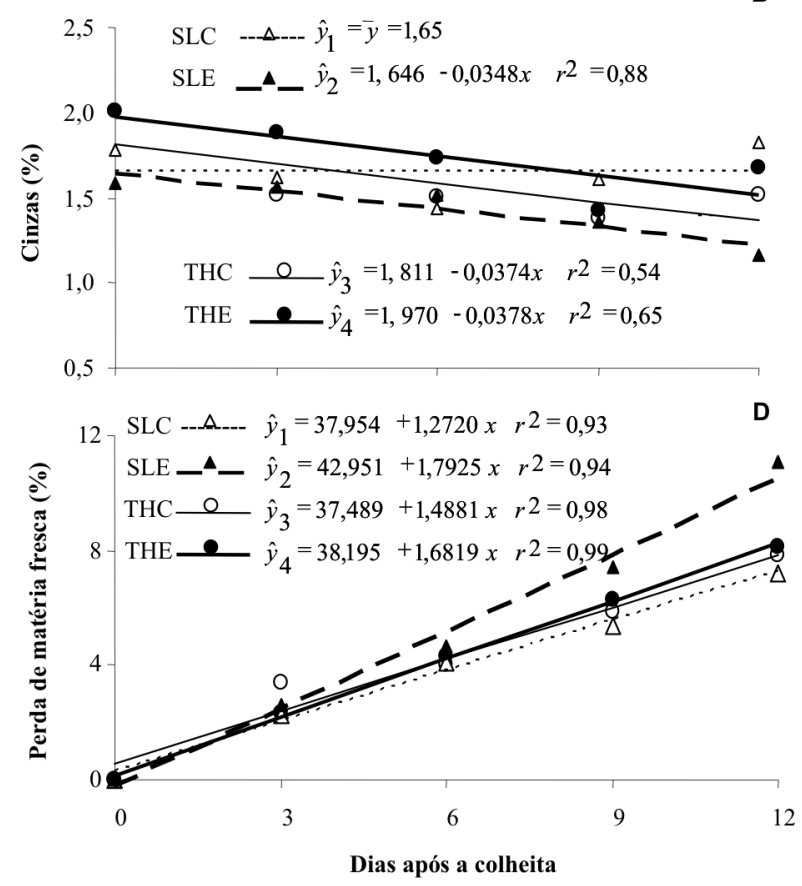

Figura 2 - Características de frutos de cubiu durante 0 armazenamento por 12 dias. A) Razão Sólidos Solúveis Totais (SST) e Acidez Total Titulável (ATT); B) Umidade; C) Cinzas; D) Perda da matéria fresca. SLC = Santa Luzia controle; SLE = Santa Luzia com Etefon (1000 $\left.\mathrm{mg} \mathrm{L}^{-1}\right)$; THC = Thais controle; THE $=$ Thais com Etefon (1000 $\left.\mathrm{mg} \mathrm{L}^{-1}\right)$. 


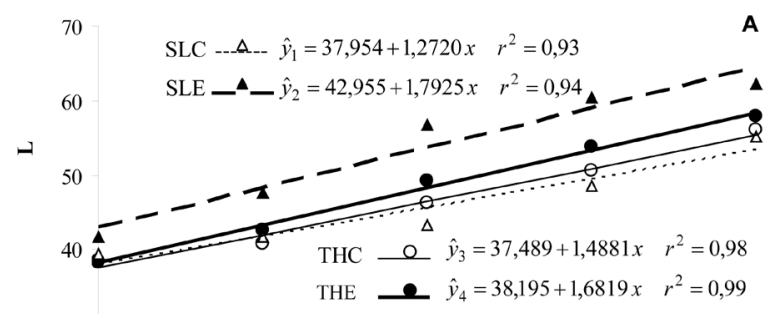

30

B

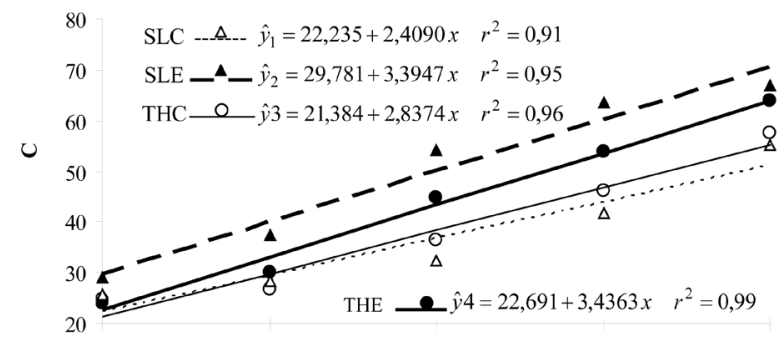

C

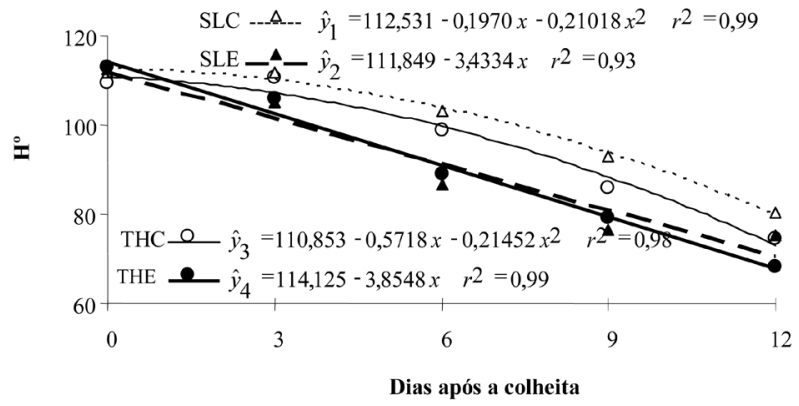

Figura 3 - Evolução da cor da casca de frutos de cubiu durante 0 armazenamento por 12 dias. A) Luminosidade (L); B) Cromaticidade (C); C) Ângulo de cor $\left(\mathrm{H}^{\circ}\right)$. SLC = Santa Luzia controle; SLE = Santa Luzia com Etefon (1000 mg L-1); THC = Thais controle; THE = Thais com Etefon (1000 mg L-1).

A aplicação de Etefon promoveu poucas mudanças na qualidade interna dos frutos de cubiu, porém foi eficiente na aceleração da mudança da cor da casca, o que pode ser verificado pelos menores valores do ângulo de cor e maiores valores da cromaticidade e luminosidade nos frutos tratados, mostrando que o etileno promoveu a degradação da clorofila. Segundo Hernández et al. (2004), a perda da cor verde dos frutos de cubiu é conseqüência da degradação da clorofila e aparecimento de pigmentos como carotenos e xantofilas que se encontram mascarados.

De modo similar, Domingues et al. (2001) concluíram que a aplicação pós-colheita de Etefon (1000 $\left.\mathrm{mg} \mathrm{L}^{-1}\right)$ em laranjas acelerou a mudança de coloração da casca, sem, entretanto, alterar a qualidade interna dos frutos. A diminuição significativa no teor de clorofila da casca foi verificada três dias após o tratamento com Etefon. A imersão rápida (dez segundos) dos frutos de abacaxi 'Pérola', logo após a colheita, em soluçóes de Etefon, nas concentraçóes de 500 a 2000 $\mathrm{mg} \mathrm{L}^{-1}$ também determinou amarelecimento mais rápido e uniforme da casca dos frutos, praticamente sem alterar a qualidade interna dos frutos (Santana et al. 2004). Os autores sugerem que o Etefon penetra muito superficialmente na casca do fruto, em grande parte não atingindo a sua polpa, além de não promover a produção endógena de etileno no abacaxi.

A atividade respiratória pós-colheita do cubiu sofreu pequenas variaçóes até o quarto dia após a colheita, em ambas as variedades e tratamentos com Etefon (Figura 4A), e não foram observadas diferenças significativas entre as variedades e Etefon, o mesmo ocorrendo com a liberação de etileno até o sétimo dia (Figura 4B, Tabela 3).

A partir do quinto dia observou-se rápido aumento na atividade respiratória em todas as combinaçôes de variedades e Etefon. $\mathrm{O}$ padráo respiratório obtido concorda com estudos anteriores conduzidos por Hernández et al. (2004) os quais sugerem que a curva de intensidade respiratória do cubiu segue o padrão típico dos frutos náo-climatéricos. Os autores atribuíram os pequenos incrementos na liberação de $\mathrm{CO}_{2}$ ao início dos processos de degradação do fruto, incrementos estes, de pequena magnitude (em torno de dois $\mathrm{mg} \mathrm{kg}^{-1} \mathrm{~h}^{-1}$ ) que ocorreram aos 9 e 16 dias de armazenamento a $15^{\circ} \mathrm{C}$ e $80 \%$ de umidade relativa.

A partir do oitavo dia pós-colheita frutos da variedade Santa Luzia tratados com Etefon exibiram aumento
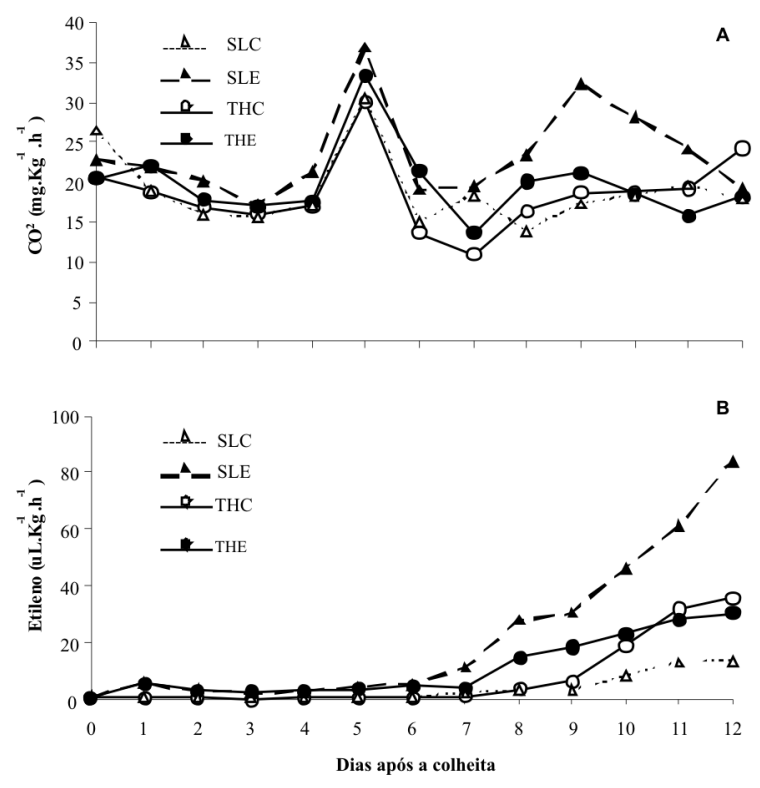

Figura 4 - Quantificação de gases liberados pelos frutos de cubiu durante 0 armazenamento por 12 dias. A) Taxa respiratória (CO2); B) Produção de etileno. SLC = Santa Luzia controle; SLE = Santa Luzia com Etefon (1000 $\mathrm{mg} \mathrm{L}-1) ; \mathrm{THC}=$ Thais controle; THE $=$ Thais com Etefon $(1000 \mathrm{mg} \mathrm{L}-1)$. 
Tabela 3 - Valores médios obtidos para a taxa respiratória $\left(\mathrm{CO}_{2}\right)$ e produção de etileno de frutos de cubiu durante 12 dias de armazenamento em função do Etefon (0 e $1000 \mathrm{mg} \mathrm{L}^{-1}$ ), das variedades Santa Luzia (SL) e Thais (TH) e do tempo (0 a 12 dias).

\begin{tabular}{|c|c|c|c|c|c|}
\hline \multirow{2}{*}{$\begin{array}{l}\text { Tempo } \\
\text { (dias) }\end{array}$} & \multirow{2}{*}{ Variedade } & \multicolumn{2}{|c|}{$\mathrm{CO}_{2}\left(\mathrm{mg} \mathrm{kg}^{-1} \mathrm{~h}^{-1}\right)$} & \multicolumn{2}{|c|}{ Etileno $\left(\mu \mathrm{Lg}^{-1} \mathrm{~h}^{-1}\right)$} \\
\hline & & 0 & 1000 & 0 & 1000 \\
\hline \multirow[t]{2}{*}{0} & SL & 26,45 a $A$ & 22,74 a A & 0,51 a $A$ & 0,52 a $A$ \\
\hline & TH & 20,55 a $A$ & 20,53 a $A$ & 0,51 a $A$ & 0,56 a $A$ \\
\hline \multirow[t]{2}{*}{1} & SL & 18,83 a $A$ & 21,87 a $A$ & 0,68 a A & 5,71 a $A$ \\
\hline & TH & 18,80 a $A$ & 22,13 a $A$ & 0,59 a $A$ & 5,45 a $A$ \\
\hline \multirow[t]{2}{*}{2} & SL & 15,80 a $A$ & 20,10 a $A$ & 0,62 a $A$ & 2,99 a A \\
\hline & TH & 16,93 a $A$ & 17,82 a $A$ & 0,52 a $A$ & 2,99 a A \\
\hline \multirow[t]{2}{*}{3} & SL & 15,60 a $A$ & 17,11 a A & 0,34 a A & 2,11 a $A$ \\
\hline & TH & 15,92 a $A$ & 17,12 a $A$ & 0,21 a $A$ & 2,26 a $A$ \\
\hline \multirow[t]{2}{*}{4} & SL & 17,09 a $\mathrm{A}$ & 21,21 a $A$ & 0,32 a $A$ & 2,71 a A \\
\hline & TH & 16,98 a A & 17,50 a $A$ & 0,28 a $A$ & 3,01 a $A$ \\
\hline \multirow[t]{2}{*}{5} & SL & 30,41 a B & 36,71 a $A$ & 0,32 a $A$ & 4,58 a $A$ \\
\hline & TH & 30,21 a $\mathrm{A}$ & 33,33 a $A$ & 0,31 a $A$ & 3,57 a $A$ \\
\hline \multirow[t]{2}{*}{6} & SL & 14,87 a $\mathrm{A}$ & 19,09 a A & 0,37 a $A$ & 4,83 a $A$ \\
\hline & TH & 13,67 a B & 21,28 a $A$ & 0,34 a A & 4,39 a $A$ \\
\hline \multirow[t]{2}{*}{7} & SL & 18,21 a $A$ & 19,35 a A & 2,12 a $A$ & 11,14 a $A$ \\
\hline & TH & 10,88 b A & 13,55 a $A$ & 0,88 a $A$ & 4,10 a $A$ \\
\hline \multirow[t]{2}{*}{8} & SL & 13,81 a $B$ & 23,25 a $A$ & 3,07 a B & 28,09 a $A$ \\
\hline & TH & 16,39 a $A$ & 20,02 a A & 3,32 a $A$ & 14,69 a $A$ \\
\hline \multirow[t]{2}{*}{9} & SL & 17,27 a B & 32,04 a A & 3,03 a B & 30,48 a $A$ \\
\hline & TH & 18,60 a $A$ & 21,09 b A & 6,27 a $A$ & 18,51 a $A$ \\
\hline \multirow[t]{2}{*}{10} & SL & 18,40 a B & 28,05 a $\mathrm{A}$ & 7,80 a B & 45,80 a $A$ \\
\hline & TH & 18,89 a $A$ & 18,46 b A & 19,00 a $A$ & 23,40 a $A$ \\
\hline \multirow[t]{2}{*}{11} & SL & 19,53 a $A$ & 24,05 a $A$ & 12,96 a $B$ & 61,12 a $A$ \\
\hline & TH & 19,17 a A & 15,83 b A & 31,73 a $A$ & $28,30 \mathrm{~b} \mathrm{~A}$ \\
\hline \multirow[t]{2}{*}{12} & SL & 17,77 b A & 19,26 a A & 13,37 a $B$ & 83,78 a $A$ \\
\hline & TH & $24,20 \mathrm{a} A$ & 18,18 a B & 35,58 a $A$ & 30,53 b A \\
\hline
\end{tabular}

Médias seguidas da mesma letra minúscula, na coluna, e maiúscula, na linha, não diferem entre si pelo teste $\mathrm{F}$ a $5 \%$ de probabilidade.

significativo na produção de etileno (Figura 4B). Porém, este aumento não parece estar relacionado ao climatério, pois coincidiu com o aparecimento de podridão na base dos frutos, causada por microrganismos, o qual possivelmente acelerou o processo de senescência e degradação. Segundo Jacomino et al. (2003), altas concentraçôes de etileno, associadas ao longo tempo de exposição, podem predispor os frutos à incidência de podridão, conforme observado com frutos de limão siciliano (Citrus lemon L.). A aplicação de Etefon pode ter efeito tóxico sobre os frutos. Os danos físicos aceleram a perda de água, conduzem à contaminaçáo por fungos nas superfícies danificadas e aumentam a taxa respiratória.

Embora frutos não-climatéricos apresentem baixa produção de etileno isso não implica que não haja interferência do etileno sobre a maturação e alguns aspectos como a diferenciação da cor da casca podem requerer etileno (Nath et al. 2006). Goldschmidt (1997) afirma que o etileno, mesmo em baixa concentração em frutos náo-climatéricos, está envolvido em eventos associados à maturaçáo, dentre eles, o aumento da atividade das clorofilases e conseqüente degradação da clorofila.

\section{CONCLUSÕES}

A pulverização dos frutos de cubiu com $1000 \mathrm{mg} \mathrm{L}^{-1}$ de Etefon promoveu poucas mudanças na qualidade interna dos frutos, na intensidade respiratória e na produção de etileno, porém foi eficiente na mudança de cor da casca, com diminuição do ângulo de cor e aumento da cromaticidade e da luminosidade, confirmando sua fisiologia de amadurecimento não-climatérica.

\section{BIBLIOGRAFIA CITADA}

Ahumada, M.; Cantwell, M. 1996. Postharvest studies on pepino dulce (Solanum muricatum Ait.): maturity at harvest and storage behavior. Postharvest Biology and Technology, 7: 129-136.

Archbold, D.D.; Pomper, K.W. 2003. Ripening pawpaw fruit exhibit respiratory and ethhylene climacterics. Postharvest Biology and Technology, 30: 99-103. 
Association of Official Analytical Chemists. 1990. Official methods of analysis of the AOAC. 9 ed. Washington. 111pp.

Brancher, A.; Tagliari, P.S. 2004. Cubiu: an Amazonian fruit in the catarinense coast. Revista Agropecuária Catarinense, 17: 43-45 (in Portuguese).

Calbo, A.G.; Nery, A.A. 1995. Measure of firmness in vegetables for the flattening technique. Horticultura Brasileira, 12: 8-14 (in Portuguese).

Domingues, M.C.S.; Ono, E.O.; Rodrigues, J.D. 2001. The effect of postharvest application of Ethephon on change peel color of sweet orange. Revista Brasileira de Fruticultura, 23: 555-558 (in Portuguese, with abstract in English).

Ferreira, D.F. 2000. The use of system SAS and SISVAR in the statistical analyses. Lavras: UFLA. 85 pp (in Portuguese).

Goldschmidt, E.E. 1997. Ripening of citrus and other non-climateric fruits: a role for ethylene. Acta Horticulturae, 463: 325-334.

Hernández, M.S.G.; Barrera, J. . G.; Páez, D.B.; Ardila, E.O.; Rubio, H.R. 2004. Biological aspects and conservation of promissory fruits of the Colombian Amazonian. Colombia: Instituto Amazónico de Investigaciones Científicas. 150 pp (in Spanish).

Jacomino, A.P.; Mendonça, K.; Kluge, R.A. 2003. Cold storage of 'Siciliano' lemon treated with ethylene. Revista Brasileira de Fruticultura, 25: 45-48 (in Portuguese, with abstract in English).

Lelièvre, J.M.; Latché, A.; Jones, B.; Bouzayen, M.; Pech, J.C. 1997. Ethylene and fruit ripening. Physiologia Plantarum, 101: 727-739.

Lima, M.A.C.; Alves, R.E.; Filgueiras, H.A.C., Enéas-Filho, J. 2003. Respiratory behavior and postharvest quality of 'Morada' soursop (Annona muricata L.) at room temperature. Revista Brasileira de Fruticultura, 25: 49- 52 (in Portuguese, with abstract in English).

Marx, F.; Andrade, E.H.A.; Maia, J.G. 1998. Chemical composition of the fruit of Solanum sessiliflorum. Zeitschrift für Lebensmitteluntersuchung und-Forschung A, 206: 364-366.

McGuire, R.G. 1992. Reporting of objective color measurements. HortScience, 27: 1254-1255.

Nath, P.; Trivedi, P.K.; Sane, V.A.; Sane, A.P. 2006. Role of ethylene in fruit ripening. p. 151-184. In: Khan, N.A. (Eds). Ethylene action in plants. Netherlands: Springer-Verlag.

Neres, C.R. L.; Vieira, G.; Diniz, E.R.; Mota, W.F.; Puiatti, M. 2004. Jilo conservation as a function of storage temperatures and plastic packing. Bragantia, 63: 431-438 (in Portuguese, with abstract in English).

Oliveira Júnior, E.N.; Santos, C.D.; Abreu, C.M.P.; Corrêa, A.D.; Santos, J.Z.L. 2004. Postharvest changes of "fruta-de-lobo" (Solanum lycocarpum St. Hil.) during the ripening process: physical-chemical, chemical and enzymatic analysis. Revista Brasileira de Fruticultura, 26: 410-413 (in Portuguese, with abstract in English).
Pardo, M.A. 2004. Effect of Solanum sessiliflorum Dunal on the lipidic metabolism and of the glucose. Ciencia e Investigación, 7: 43-48 (in Spanish, with abstract in English).

Pires, A.M.B.; Silva, P.S.; Nardelli, P.M.; Gomes, J.C.; Ramos, A.M. 2006. Characterization and processing of cubiu (Solanum sessiliflorum). Ceres, 53: 309-316 (in Portuguese, with abstract in English).

Santana, L.L.A.; Reinhardt, D.H.; Medina, V.M.; Ledo, C.A.S.; Caldas, R.C.; Peixoto, C.P. 2004. Effects of application methods and concentrations of ethephon on rind color and other quality attributes of 'Pérola' pineapples. Revista Brasileira de Fruticultura, 26: 212-216 (in Portuguese, with abstract in English).

Silva Filho, D.F.; Clement, C.R.; Noda, H. 1989. Phenotypic varition in fruits of 12 provenences of cubiu (Solanum sessiliflorum Dunal) evaluated in Manaus, AM, Brazil. Acta Amazonica, 19: 9-18 (in Portuguese, with abstract in English).

Silva Filho, D.F.; Anunciação, C.J.; Noda, H.; Reis, O.V. 1996. Genetic variability in natural populations of Orinoco apple (Solanum sessiliflorum) of the Amazon. Horticultura Brasileira, 14: 9-15 (in Portuguese, with abstract in English).

Silva Filho, D.F.; Andrade, J.S.; Clement, C.R.; Machado, F.M.; Noda, H. 1999. Phenotypic, genetic and environmental correlations between morphological and chemical descriptors in fruits of cubiu (Solanum sessiliflorum Dunal) in Amazonia. Acta Amazonica, 29: 503-511 (in Portuguese, with abstract in English).

Silva Filho, D.F. 2002. Discrimination of ethnovarieties of cubiu (Solanum sessiliflorum Dunal, Solanaceae) of Amazonia, based on their morphological and chemical characteristics. Tese de Doutorado, Universidade Federal do Amazonas, Manaus, Amazonas. 116 pp (in Portuguese).

Silva Filho, D.F.; Yuyama, L.K.O.; Aguiar, J.P.L.; Oliveira, M.C.; Martins, L.H.P. 2005. Characterization and evaluation of the agronomic and nutritional potential of ethnovarieties of cubiu (Solanum sessiliflorum Dunal) in Amazonia. Acta Amazonica, 35: 399-406 (in Portuguese, with abstract in English).

Storti, E.F. 1988. Floral biology of Solanum sessiliflorum Dun. var. sessiliflorum, in the Manaus region, Amazonia. Acta Amazonica, 18: 55-65 (in Portuguese, with abstract in English).

Villachica, H. 1996. Fruit trees and promissory vegetables of the Amazonia. Lima: Tratado de Cooperación Amazónica, Secretaría Pro-Tempore. 367 pp (in Spanish).

Yuyama, L.K.O.; Macedo, S.H.M.; Aguiar, J.P.L.; Silva Filho, D.; Yuyama, K.; Fávaro, D.I.T.; Vasconcelos. M.B.A. 2007. Macro and micro nutrients quantification of some cubiu ethnovarieties (Solanum sessiliflorum Dunal). Acta Amazonica, 37: 425-430 (in Portuguese, with abstract in English).

Recebido em 10/10/2008

Aceito em 14/12/2009 